\title{
Leprosy in the post-elimination era: a clinico-epidemiological study from a northern Indian tertiary care hospital
}

\author{
Tasleem Arif $^{1 凶}$, Syed Suhail Amin ${ }^{1}$, Mohammad Adil ${ }^{1}$, Konchok Dorjay ${ }^{1}$, Dinesh Raj $^{1}$
}

\begin{abstract}
Introduction: Leprosy is a chronic disease caused by Mycobacterium leprae. Despite being eliminated from India in 2005, there are still a considerable number of leprosy cases.

Methods: A prospective hospital-based study involving all leprosy patients attending the leprosy clinic at the Department of Dermatology from January 2015 to December 2016.

Results: A total of 220 patients visited the leprosy clinic during the study period. Most of the patients ( $48.7 \%$ ) were 20 to 40 years old. Multibacillary disease was more common in females (84.7\%) than males (67.6\%), and in rural patients (80.9\%) than urban patients $(64.8 \%)$. Borderline lepromatous leprosy was the most common (38.2\%) type of leprosy seen, followed by lepromatous leprosy (28.2\%) and borderline tuberculoid leprosy (21.4\%).

Conclusions: Despite elimination, leprosy continues to be a health problem in this part of the world. We have shown that females and the rural population are more susceptible to multibacillary disease.
\end{abstract}

Keywords: borderline lepromatous, borderline tuberculoid, leprosy, multibacillary disease, Mycobacterium leprae

Received: 12 April 2018 | Returned for modification: 22 November 2018 | Accepted: 12 December 2018

\section{Introduction}

Leprosy, or Hansen's disease, is a chronic disease that primarily involves the skin and peripheral nerves. It has a variety of clinical presentations, depending on the cell-mediated immunity of the host. It has been classified by the World Health Organization (WHO) as a paucibacillary disease and multibacillary disease depending on the number of lesions. The Ridley-Jopling classification of leprosy divides the disease into five groups: tuberculoid (TT), borderline tuberculoid (BT), mid-borderline (BB), borderline lepromatous (BL), and lepromatous (LL). The Indian classification includes an additional pure neuritic variant. The diagnosis of leprosy is clinical, but a slit skin smear and histopathology are means to aid diagnosis (1).

Despite being known to mankind since time immemorial and the discovery of the causative agent more than a century ago, many aspects of the epidemiology and pathogenesis of leprosy still remain to be fully elucidated. Sustained efforts helped India achieve elimination targets of leprosy in 2005 (i.e., a prevalence of less than one case per 10,000 at the national level). Despite this, leprosy remains a health concern in India. More than $60 \%$ of all new leprosy patients detected in the world were Indians (2). The prevalence of leprosy currently stands at 0.68 cases per 10,000 population per 2012-2013 data (3). Although this share seems small, it corresponds to a huge number of leprosy cases on the ground due to India's large population. This inspired the authors to carry out a prospective study at our leprosy clinic to determine its clinical-epidemiological trends in our population.

\section{Methods}

We conducted a prospective study on all new leprosy patients attending the leprosy clinic at the dermatology department at our hospital. The duration of our study was 2 years, from January 2015 to December 2016. The data collected included the patients' age, sex, residence, and type of leprosy. Informed consent (verbal and written) was provided by the patients or their guardians for slit skin smear examination and skin biopsy for participation in the study, and for subsequent publication of the data, which may also contain their personal details, including their images. Consent for nerve biopsy was obtained in selective cases. The patients were enrolled in the study only after meeting the above requirements for consent. The patients were diagnosed on the basis of clinical signs and symptoms, and the diagnosis was confirmed by slit skin smear and skin histopathology in all cases. Regarding leprosy reactions, only those cases of reactions were added to the database in which the initial presentation at the time of enrollment in the study was a reaction. However, reactions developing later during follow-up were not added to the database.

\section{Clinical diagnosis}

Any patient with one of the following symptoms was provisionally diagnosed with leprosy, and the diagnosis was further augmented with histopathological examination of a skin biopsy: a) hypopigmented or erythematous skin lesion(s) with either definite loss or impairment of sensation, b) peripheral nerve involvement as demonstrated by definite thickening with sensory impairment, and c) slit skin smear examination positive for acid-fast bacilli.

\section{Classification of disease}

The disease was classified according to Jopling's classification into five categories: TT, BT, BB, BL and LL (1). Patients presenting only with nerve thickenings and impairment of sensations without skin lesions were diagnosed as having pure neuritic leprosy, and their diagnosis was confirmed by nerve biopsy employing the sural nerve. Histoid leprosy was diagnosed when patients presented 
with papular and nodular lesions, confirmed by histopathology through the predominance of spindle-shaped cells and unusually large numbers of acid-fast bacilli.

\section{Multibacillary and paucibacillary disease}

Multibacillary disease was considered when patients had more than five skin lesions or more than one nerve involvement or skin smear positive at any site. Paucibacillary disease was diagnosed if there were five or fewer skin lesions or no nerve involvement, or if there was only one nerve involved and the skin smear was negative at all sites. At any point in time, skin smear positivity was considered multibacillary disease irrespective of the number of skin lesions or number of nerves involved (1).

\section{Treatment of leprosy}

WHO multidrug therapy was used in the management of leprosy. Paucibacillary disease was treated with rifampicin $600 \mathrm{mg}$ once a month (supervised) and dapsone $100 \mathrm{mg}$ daily (self-administered) for a duration of 6 months, which has to be completed within 9 months. Multibacillary disease was treated with rifampicin 600 mg once a month (supervised), dapsone $100 \mathrm{mg}$ daily (self-administered) and clofazimine $300 \mathrm{mg}$ once a month (supervised), and $50 \mathrm{mg}$ daily (self-administered) for a total duration of 12 months, which has to be completed within 18 months. The patients received their drugs in monthly calendar blister packs. For children over 10 years, the drug doses were rifampicin $450 \mathrm{mg}$ (300 mg + $150 \mathrm{mg}$ ) once a month, dapsone $50 \mathrm{mg}$ daily, and clofazimine 150 (three 50 $\mathrm{mg}$ capsules) once a month and $50 \mathrm{mg}$ daily. For children younger than 10 years, the dose was adjusted according to body weight.

The statistical method used in the study for comparison between groups was the chi-square test. A $p$-value less than 0.05 was considered statistically significant.

\section{Results}

A total of 220 new leprosy patients attended the leprosy clinic during the study period. Of these, 148 were males and 72 were females $(p=0.03)$. The various characteristics of the patients are presented in Tables 1, 2, and 3.

Table 1 | Distribution of patients by age.

\begin{tabular}{lcc}
\hline Age (years) & $n$ & $\%$ \\
\hline 10 & 2 & 0.9 \\
$11-20$ & 42 & 19.1 \\
$21-30$ & 49 & 22.3 \\
$31-40$ & 58 & 26.4 \\
$41-50$ & 41 & 18.6 \\
$51-60$ & 23 & 10.4 \\
$>60$ & 5 & 2.3 \\
\hline Total & 220 & 100.0 \\
\hline
\end{tabular}

Table 2 | Distribution of patients by sex and type of leprosy.

\begin{tabular}{l|cc|cc|cc}
\hline \multirow{2}{*}{ Leprosy type } & \multicolumn{2}{|c|}{ Males } & \multicolumn{2}{c|}{ Females } & \multicolumn{3}{c}{ Total } \\
\cline { 2 - 7 } & $\mathrm{n}$ & $\%$ & $\mathrm{n}$ & $\%$ & $\mathrm{n}$ & $\%$ \\
\hline TT & 10 & 4.5 & 2 & 0.9 & 12 & 5.4 \\
BT & 38 & 17.3 & 9 & 4.1 & 47 & 21.4 \\
BB & 6 & 2.7 & 3 & 1.4 & 9 & 4.1 \\
BL & 48 & 21.8 & 36 & 16.4 & 84 & 38.2 \\
LL & 40 & 18.2 & 22 & 10.0 & 62 & 28.2 \\
Other & 6 & 2.7 & 0 & 0.0 & 6 & 2.7 \\
\hline Total & 148 & 67.3 & 72 & 32.7 & 220 & 100.0
\end{tabular}

$\mathrm{TT}=$ tuberculoid leprosy, $\mathrm{BT}=$ borderline tuberculoid, $\mathrm{BB}=$ mid-borderline, $\mathrm{BL}=$ borderline lepromatous, $\mathrm{LL}=$ lepromatous leprosy.
Table 3 | Distribution of patients by residence and type of leprosy.

\begin{tabular}{l|cc|cc|cc}
\hline \multirow{2}{*}{ Leprosy type } & \multicolumn{2}{|c|}{ Rural } & \multicolumn{2}{c|}{ Urban } & \multicolumn{3}{c}{ Total } \\
\cline { 2 - 7 } & $\mathrm{n}$ & $\%$ & $\mathrm{n}$ & $\%$ & $\mathrm{n}$ & $\%$ \\
\hline TT & 6 & 2.7 & 6 & 2.7 & 12 & 5.4 \\
$\mathrm{BT}$ & 16 & 7.3 & 31 & 14.1 & 47 & 21.4 \\
$\mathrm{BB}$ & 6 & 2.7 & 3 & 1.4 & 9 & 4.1 \\
$\mathrm{BL}$ & 52 & 23.6 & 32 & 14.5 & 84 & 38.2 \\
LL & 33 & 15.0 & 29 & 13.2 & 62 & 28.2 \\
Other & 2 & 0.9 & 4 & 1.8 & 6 & 2.7 \\
\hline Total & 115 & 52.3 & 105 & 47.7 & 220 & 100.0 \\
\hline
\end{tabular}

$\mathrm{TT}=$ tuberculoid leprosy, $\mathrm{BT}=$ borderline tuberculoid, $\mathrm{BB}=$ mid-borderline, $\mathrm{BL}=$ borderline lepromatous, $\mathrm{LL}=$ lepromatous leprosy.

Multibacillary disease was confirmed in $161(73.2 \%)$ patients, of whom nine (4.1\%) patients were in the BB segment, $84(38.2 \%)$ patients in the BL segment, and $62(28.2 \%)$ patients had LL disease. One hundred males (67.6\%) and 61 females (84.7\%) had multibacillary disease, implying that multibacillary disease is more prevalent than the paucibacillary type, and it was statistically significant $(p=0.003)$. Multibacillary disease was seen in $93(80.9 \%)$ rural patients and $68(64.8 \%)$ urban patients, and this approached statistical significance $(p=0.05)$.

Paucibacillary disease was seen in $59(26.8 \%)$ patients. Of the 59 patients with paucibacillary disease, 12 (5.4\%) had TT and 47 (21.4\%) had BT disease. There were also two patients with histoid leprosy and four patients with pure neuritic leprosy. Out of 148 males, 48 (32.4\%) had paucibacillary disease, whereas only $11(15.3 \%)$ females had this disease. Twenty-two rural patients (19.1\%) had paucibacillary disease and 37 urban patients (35.2\%) had the same.

Three patients (1.4\%) presented to us with type 1 reaction and 21 patients (9.5\%) presented with type 2 reaction at the first visit. Twenty-two patients (10\%) had grade 1 deformity and four patients (1.8\%) presented with a trophic ulcer. Six patients $(2.7 \%)$ defaulted on their treatment and did not complete it.

\section{Discussion}

The mean age of our patients was 35, with the youngest 8 years old and oldest two patients 80 years old. More than $80 \%$ of patients were between 11 and 50 years old. The greatest numbers of patients were 31 to 40 years old. The incidence of leprosy is said to rise between ages 10 and 20 and to peak between ages 20 and 35 (4). Other studies also corroborate this finding $(5,6)$. Leprosy in children (16 years or younger) was of the same proportion as observed in other studies $(5,7,8)$. The share of children with multibacillary disease was $69.2 \%$. Similar results were shown by Mukherjee et al., who found $61.3 \%$ of children with multibacillary disease (9). However, other studies have shown that paucibacillary disease is more common in children (10). This disparity may be due to a delay in seeking medical care due to poor socioeconomic status and lack of awareness. The male:female ratio in our study was 2:1. This is in accordance with other recent studies from India showing almost the same results for predilection by sex (5, 9). Although leprosy has been associated with male gender since the sulfone era (11), the much greater incidence among males in our study might be attributed to their greater mobility and increased accessibility to healthcare (12). The number of patients from rural areas slightly outnumbered people from urban areas. A study from the western Indian state of Maharashtra found that the prevalence of the disease and number of new cases was greater in urban areas (13). This disparity of findings can best be explained by the large proportion of rural patients that our hospital attracts 
from all over western Uttar Pradesh, an indicator of the lack of availability of good medical care facilities in rural areas.

In our study, $73.2 \%$ patients had multibacillary disease. This corresponds to the percentage of multibacillary cases in our state as well as other studies $(9,14,15)$. However, some studies have reported a slightly lower percentage of multibacillary cases (8, 16). The proportion of leprosy cases with multibacillary disease is reflective of patients that are a major source of infection and are also susceptible to reactions and consequently deformities (16, 17). The greater proportion of multibacillary leprosy cases also indicates the inability of health services to diagnose early cases of leprosy. Moreover, patients tend to hide their lesions due to the associated stigma. The greater number of multibacillary cases in our study is probably due to these reasons because our hospital caters to the most underprivileged section of society in the economically backward Indian state of Uttar Pradesh. A total of 63.6\% patients were in the borderline category (including BT, BL, and BB disease), whereas $28.2 \%$ had LL and only $5.4 \%$ presented to us with TT. Borderline cases have become more common since the introduction of multidrug therapy as opposed to the polar forms of the disease that were more commonly seen in the dapsone era (11, 18-20). The low percentage of polar TT in our study is similar to observations by Jindal et al., who reported $5.52 \%$ cases of TT (21). We found that a higher percentage of female patients than male patients had multibacillary disease. This is in contrast to the observations of other studies, which report the multibacillary form of leprosy to be more common in males (9). Arora et al. found the number of males and females with LL to be almost equal, but the $\mathrm{BL}$ and $\mathrm{BB}$ cases were more common in females (15). The increased number of females with multibacillary disease in our study might be explained by the poor socioeconomic status of females, leading to delay in seeking medical care. Most of the women in our study were also married and engaged in the household activities, which can serve as a barrier for reporting their disease. In low socioeconomic conditions, the husband works long hours for the family and it is difficult for him to leave work and accompany his wife to the hospital. Apart from this, the stigma of leprosy has a more marked effect on females than males, which can further delay a woman's appointment for her skin lesions if she suspects leprosy. Urban patients in our study had a lower percentage multibacillary disease compared to patients from rural areas. Mohite et al. also found that multibacillary disease was more commonly diagnosed if the patient came from a rural area (13). This is possibly due to the rural population's lack of access to medical facilities.

Lepra reactions were seen in $10.9 \%$ of patients, with type 2 reaction being much more common than type 1 reaction. Similar observations were made by Salodkar et al., who observed reactions in $11.1 \%$ of cases, with type 2 reaction being four times more frequent than type 1 reaction (22). This implies that many patients ignore their disease and seek medical care only when they develop reactions. Other studies have shown an even higher percentage of patients presenting with lepra reactions $(15,16,23)$. It is worth noting that we documented patients for reactions only at the patient's first visit. These data do not include patients that developed reactions after treatment was initiated. The number of defaulters in our study was $2.7 \%$. Good counselling of patients is necessary to maintain patient adherence to treatment. Type 1 lepra reaction is associated with a sudden alteration of cell-mediated immunity associated with a shift in the patient's position in the leprosy spectrum. Type 1 reaction is type IV hypersensitivity reaction usually observed in the borderline spectrum of the disease. There is an increase in inflammation of some or all preexisting skin patches or plaques, which become erythematous, swollen, and tender. Type 2 lepra reaction $\left(\mathrm{T}_{2} \mathrm{R}\right)$ is usually associated with immune complexes and is observed in LL. It is an example of type III hypersensitivity reaction and is usually associated with systemic symptoms. Clinically, there is a sudden appearance of crops of new evanescent, pink to rose-colored papules, nodules, or plaques varying in size that are painful and tender to the touch (24). In our study, type 2 reaction scored more than type 1 probably because our study population had a good number of LL cases. In addition, these cases were first-time presentations of the disease as a reaction and not follow-up cases that subsequently developed reactions.

Various control and preventive programs are already underway in India. These include the national leprosy control program, national leprosy eradication program, modified leprosy elimination campaign, and national rural health mission. Integration of leprosy services with the general care system to cover the entire population, trained leprosy workers at the peripheral level, regular surveillance of new cases at the community level, improving the quality of services, improving community awareness and involvement, and home visits to diagnosed patients are preventive and control measures that are being carried out. An accredited social health activist (ASHA) is one of the key components of the national rural health mission. The ASHA is a female health activist that belongs to village, and so she can be used to reach female leprosy patients specifically (25).

Because our study was conducted at a tertiary care hospital, it certainly is not representative of the situation in the field. Nonetheless, it offers a general picture of current leprosy trends in the region. The large percentage of patients with multibacillary cases, particularly females and mostly from the rural population, indicates that leprosy awareness and control programs aimed at elimination need to be more vigorously implemented to targeting these segments.

\section{Conclusions}

Leprosy may have been eliminated from this part of the world, but it definitely continues to be a health concern. The total number of cases is large, although the percentage is low. This warrants effective and vigorous implementation of awareness about the disease, facilities for investigation, and unhindered provision of therapy. The occurrence of the disease in children is a cause of concern and signifies active disease transmission. Newer strategies to target susceptible groups need to be devised to achieve complete eradication of this menace from society.

\section{References}

1. Arif T, Dorjay K, Adil M, Sami M. Classification of leprosy - from past to present. J Pakistan Assoc Dermatol. 2018;28:95-9.
2. World Health Organization. Global leprosy update 2014: need for early case detection. Wkly Epidemiol Rec. 2015;90;461-74. 
3. Park K. Park's textbook of preventive and social medicine. 22nd ed. Jabalpur: Banarsidas Bhanot; 2013.

4. Wu XS, Ning Y, Shi L, Jin Z, Yang JW. An epidemiological analysis of leprosy from 1951-1996 in Sinchuan. Indian J Lepr. 2000;72:215-26.

5. Thakkar S, Patel SV. Clinical profile of leprosy patients: a prospective study. Indian J Dermatol. 2014:59:158-62.

6. Philip M, Samson JF, Simi PS, Ebenezer S. An epidemiological study of leprosy cases at a tertiary hospital in South Kerala. Int J Current Research. 2014;6:78545.

7. Casabianca MN. Leprosy situation in Uttar Pradesh 1991-2005: prevalence, case detection and other indicators over a 15-year period. Indian J Lepr. 2006;78: 137-43.

8. Pandey A, Patel R, Rathod H. Comparative profile of new leprosy cases coming to a referral institute in pre- and post- integration periods. Indian J Lepr. 2006; 78:339-46.

9. Mukherjee PK, Das P, Rao PSS. Time trends in MB-PB ratio among untreated leprosy patients attending a referral hospital in UP, India during 2001 to 2010. Indian J Lepr. 2013;85:59-64.

10. Palit A, Inamdar AC, Desai SS, Sharma P. Childhood leprosy in the post elimination phase: data from a tertiary care hospital in the Karnataka state of south India. Lepr Rev. 2014;85:85-92.

11. Norman G, Bhushanam JDRS, Samuel P. Trends in leprosy over fifty years in Gudiyatham Taluk, Vellore, Tamilnadu. Indian J Lepr. 2006;78:105-11.

12. Richardus JS, Meima A, Croft RP, Habbema JD. Case detection, gender and disability in leprosy in Bangladesh: a trend analysis. Lepr Rev. 1999;70:160-73.

13. Mohite RV, Mohite VR, Durgawale PM. Differential trend of leprosy in rural and urban area of western Maharashtra. Indian J Lepr. 2013;85:11-8.

14. Mahajan VK, Sharma NL, Rana P, Sood N. Trends in detection of new leprosy cases at two centers in Himachal Pradesh, India: a ten-year study. Indian J Lepr. 2003;75;17-24.
15. Arora M, Katoch K, Natrajan M, Kamal R, Yadav VS. Changing profile of disease of leprosy patients diagnosed in a tertiary care centre during years 1995-2000. Indian J Lepr. 2008;80:257-65.

16. Kumar B, Dogra S, Kaur I. Epidemiological characteristics of leprosy reactions: 15 years experience from north India. Int J Lepr Other Mycobact Dis. 2004;72: 125-33.

17. van Brakel WH, Kahwas IB. Nerve function impairment in leprosy: an epidemiological and clinical study-part 2: results of steroid treatment. Lepr Rev. 1996; 67:104-18.

18. Ramu G. Clinical leprosy through the last seventy-five years. Indian J Lepr. 2000; 72:199-214.

19. Sharma A, Sharma RK, Goswsami KC, Bardwaj S. Clinico-histopathological correlation in leprosy. JK Science. 2008;10:120-3.

20. Shenoi SD, Siddappa K. Correlation of clinical and histopathologic features in untreated macular lesions of leprosy: a study of 100 cases. Ind J Lepr. 1988;60:2026.

21. Jindal N, Shanker V, Tegta GR, Gupta M, Verma GK. Clinico-epidemiological trends of leprosy in Himachal Pradesh: a five-year study. Indian J Lepr. 2009;81:173-9.

22. Salodkar AD, Kalla G. A clinico-epidemiological study of leprosy in arid north west Rajasthan, Jodhpur. Ind J Lepr. 1995;57:161-6.

23. Leinhardt C, Fine PEM. Type 1 reaction, neuritis and disability in leprosy: what is the current epidemiological situation? Lepr Rev. 1994;65:9-33.

24. Kar HK, Sharma P. Leprosy reactions. In: Kar HK, Kumar B, editors. IAL textbook of leprosy, 1st ed. New Delhi: Jaypee Brothers Medical Publishers; 2010. p. 269-73.

25. Joshi P. Nadonal Scenario, National Leprosy Eradication Program (NLEP) and new paradigms. In: Kar HK, Kumar B, editors. IAL textbook of leprosy. 1st ed. New Delhi: Jaypee Brothers Medical Publishers; 2010. p. 35 